\title{
SARCOIDOSIS AND LUNG CANCER
}

\author{
Naohiro Kobayashi ${ }^{1}$, Ryota Nakamura ${ }^{1}$, Koichi Kurishima ${ }^{2}$, Yukio Sato ${ }^{1}$, Hiroaki Satoh ${ }^{3}$ \\ University of Tsukuba, Institute of Clinical Medicine, Tsukuba, Japan: Divisions of Thoracic Surgery ${ }^{1}$, Respiratory \\ Medicine $^{2}$, Mito Medical Center ${ }^{3}$
}

\begin{abstract}
Summary: Background: Although sarcoidosis as well as lung cancer are frequently encountered common diseases, their metachronous or synchronous occurrence in the same patient is very rare. Methods: The charts of lung cancer patients, diagnosed between 1980 and 2007 in our hospital, were reviewed. Results: We found 3 cases with sarcoidosis and lung cancer. The first case had lung cancer 16 years after the diagnosis of sarcoidosis. The second case had two different metachronous lung cancers 18 and 10 years after the diagnosis of sarcoidosis. The third case detected these two diseases simultaneously. In simultaneously detected cases, it is difficult to determine whether noncaseating epithelioid cell granulomas coexisting with lung cancer represent sarcoid reaction or genuine systemic sarcoidosis. Conclusions: Either causality or coincidence, lung cancer, a condition that can be observed in patients with sarcoidosis, should be considered in the differential diagnosis when suspicious findings of it are discovered.
\end{abstract}

Key words: Sarcoidosis; Lung cancer; Sarcoid reaction

\section{Introduction}

Sarcoidosis is a systemic granulomatous disease of unknown etiology and is characterized by $\mathrm{T}$ cells dysfunction (13). In these patients, the higher prevalence of malignancy, both hematological and non-hematological, has well been studied $(1,2,3,4,5,11,12,16,18,20)$. The occurrence of sarcoidosis and lung cancer has raised question on the potential combination of these two pathologies $(3,4,5,12,16$, $18,20,21)$. We herein report 3 cases of metachronous or simultaneous sarcoidosis and lung cancer.

\section{Case reports}

Case No. 1

A 45-year-old man was admitted to our hospital for bilateral uveitis. On chest CT scan, he had bilateral hilar and left mediastinal lymphadenopathies, in which showed abnormal uptake in gallium scintigraphy. He was diagnosed as having sarcoidosis on the basis of uveitis, lymphadenopathies, and pathological findings of noncaseating epithelioid cell granulomas, which were observed in the mediastinal lymph nodes obtained by mediastinoscopy. Sarcoidosis had been treated by steroid. Sixteen years after the diagnosis of sarcoidosis, a chest radiograph, which was performed as an annual check-up for bilateral hilar lymphadenopathy (BHL), demonstrated a mass located in the left lower lobe (Fig. 1). Transbronchial biopsy revealed squamous cell carcinoma, then, left lower lobectomy was performed. Pathological findings were squamous cell carcinoma of the size of $3.5 \mathrm{~cm}$ without any lymph node metastasis. There were sarcoid granulomas in the lung parenchyma and hilar lymph nodes. He was well with no recurrence for 6 years.

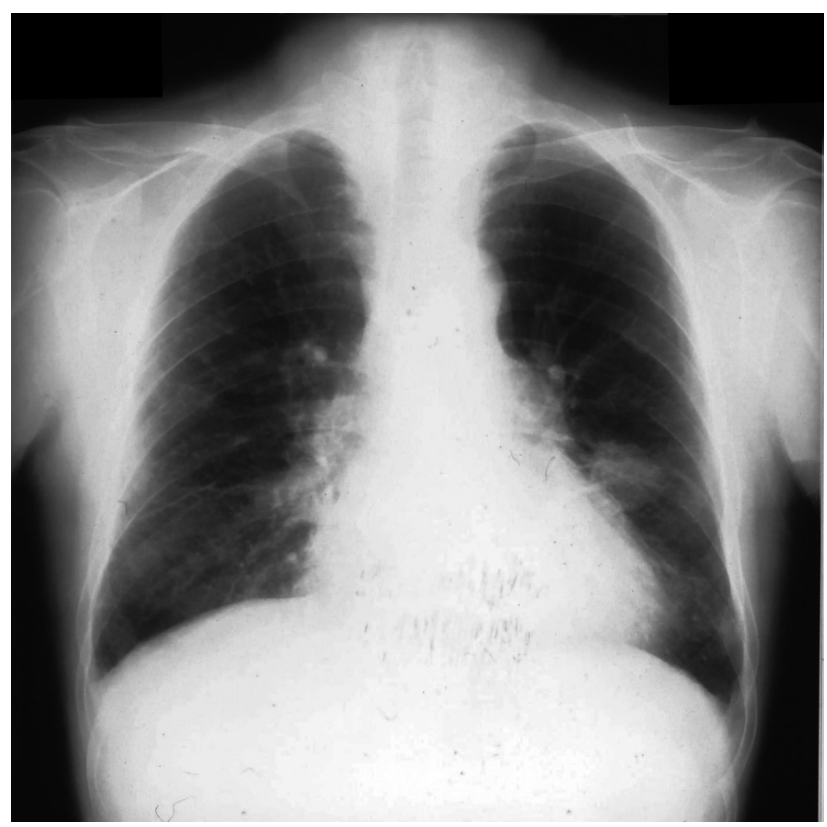

Fig. 1: A chest radiograph, which was performed as an annual check-up for bilateral hilar lymphadenopathy, demonstrated a mass located in the left lower lobe. 


\section{Case No. 2}

A 51-year old man was referred to our hospital for erythema nodosum on his bilateral arms. He had bilateral hilar lymphadenopathy on chest CT scan. Gallium scintigraphy showed abnormal accumulation in these lymph nodes. Biopsy of the skin lesion showed noncaseating epithelioid cell granulomas. During the follow-up period, he developed angina pectoris. Ten years after the diagnosis of sarcoidosis, chest radiograph, which was performed as an annual check-up for angina and BHL, revealed a chest abnormal mass in right upper lobe (Fig. 2). Transbronchial biopsy could not diagnose it. Therefore, partial resection of the lobe was performed. Pathological finding was large cell carcinoma of size of $1.2 \mathrm{~cm}$. He was observed carefully without adjuvant therapy. But 8 years later he had another mass in the residual part of the right upper lobe. Transbronchial biopsy revealed squamous cell carcinoma. As he had no metastatic lesion, he received right upper lobectomy. Pathological findings were squamous cell carcinoma of size of $5.2 \mathrm{~cm}$ with right hilar lymph node metastasis. Sarcoid granuloma did not exist in the lung and lymph nodes. Adjuvant therapy was not performed because of his poor post-operative condition. He was alive for 2 years after the lobectomy for the second primary lung cancer.

\section{Case No. 3}

A 60-year-old woman was admitted to our hospital because of a mass in the right lung in a chest radiograph taken at annual medical check-up (Fig. 3). She had no symptom, but chest CT scan showed a nodule of size of $2.3 \mathrm{~cm}$ in right upper lobe with ipsilateral mediastinal lymphadenopathy. A diagnosis of adenocarcinoma was made by trans-

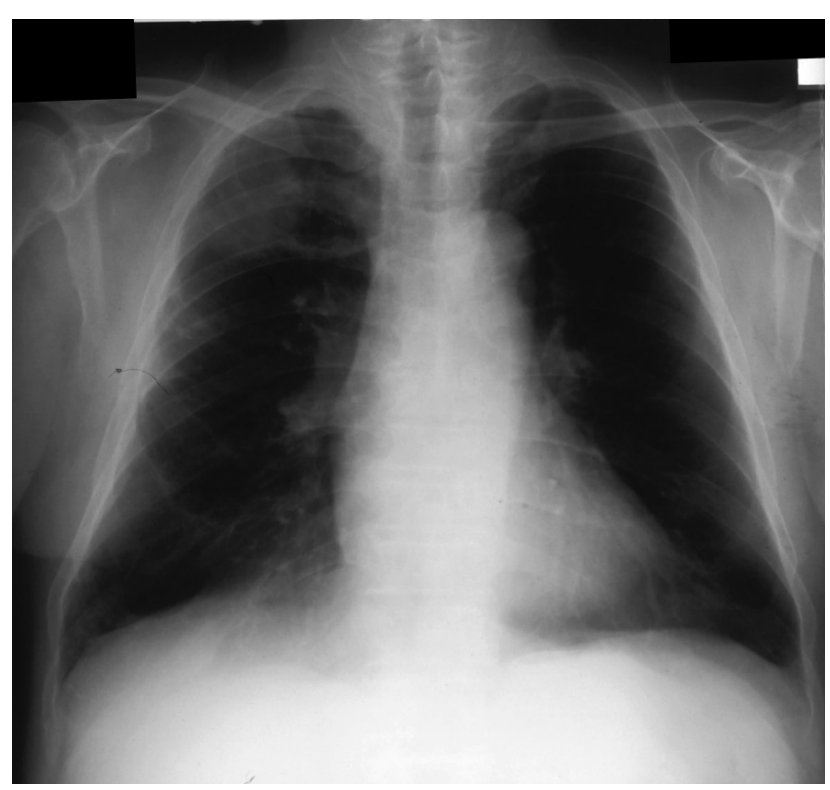

Fig. 2: Chest radiograph, which was performed as an annual check-up for angina and BHL, revealed a chest abnormal mass in right upper lobe of the lung. bronchial tumor biopsy. Thereafter, right upper lobectomy was performed. Pathological finding of the lesion was adenocarcinoma. And noncaseating epithelioid cell granulomas existed in the resected ipsilateral hilar and mediastinal lymph nodes and the lung apart from adenocarcinoma. There was no metastasis in these lymph nodes. One month after the surgery, gallium scintigraphy was performed and it showed abnormal accumulations in left hilar lymph nodes. A diagnosis of sarcoidosis was made and followed with no medication. She is still well for 10 months.

\section{Discussion}

The higher prevalence of malignancy, both hematological and non-hematological, in patients with sarcoidosis has well been studied $(1,4,5,11,12,16,18,20,21)$. In most cases, the diagnosis of sarcoidosis is followed chronologically by malignant disease with few cases of coexisting disease (1, $4,5,11,12,16,18,20,21)$. Same as other malignant diseases, lung cancer develops several years after the diagnosis of sarcoidosis, but in some cases, both diseases are detected simultaneously $(1,3,4,5,12,16,18,20.21)$. We summarized clinicopathological characteristics and outcomes of our three cases in Table 1 and 2. According to a report by Yamasawa et al (20), there have been four speculations concerning the causal relationship between sarcoidosis and lung cancer; 1) the two diseases incidentally coexist, 2) the cell-mediated immune abnormalities induced by sarcoidosis are involved in the onset of lung cancer, 3 ) lung cancer originates in the fibrous tissue due to sarcoidosis, and 4) the onset of sarcoidosis is caused by an immunohistological reaction such as sarcoid reactions, which respond to malig-

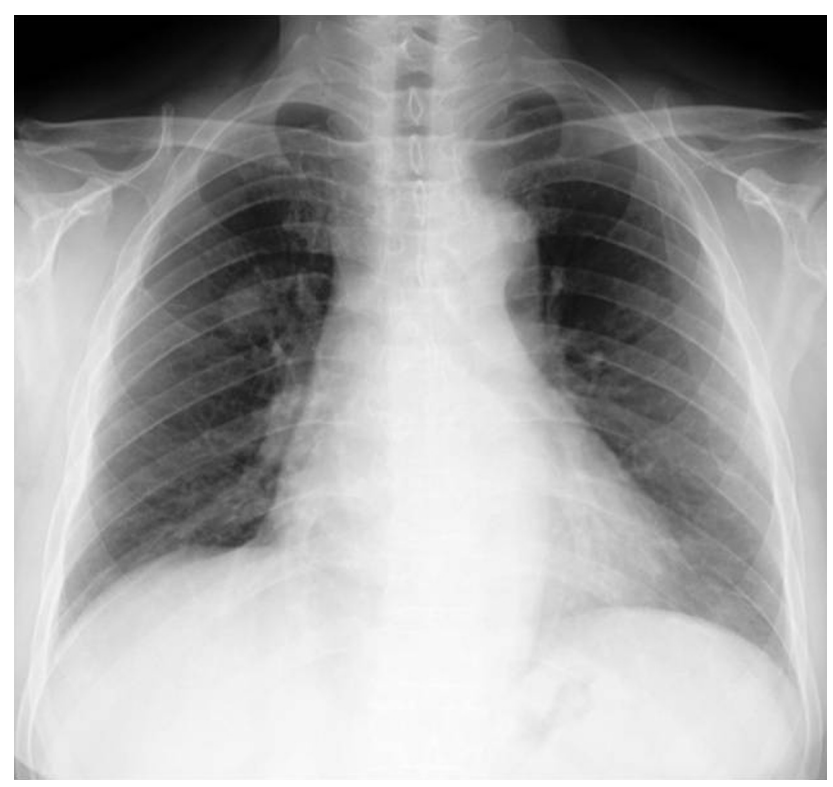

Fig. 3: Chest radiograph, which was taken at annual medical check-up, showed a mass in the right lung. 
Tab. 1: Characteristics of 3 patients with sarcoidosis and lung cancer.

\begin{tabular}{|c|c|c|c|c|c|c|c|}
\hline \multirow[b]{2}{*}{ No. } & \multirow[b]{2}{*}{ Age\#/Sex } & \multirow{2}{*}{$\begin{array}{l}\text { Smoking } \\
\text { index }\end{array}$} & \multirow{2}{*}{$\begin{array}{l}\text { Performance } \\
\text { status }\end{array}$} & \multicolumn{2}{|c|}{ Lung cancer } & \multirow{2}{*}{$\begin{array}{l}\text { Lesions of } \\
\text { sarcoidosis }\end{array}$} & \multirow{2}{*}{$\begin{array}{c}\text { Interval } \\
\text { between } \\
2 \text { diseases }\end{array}$} \\
\hline & & & & Pathology & c-TNM & & \\
\hline 1 & 45/Male & 300 & 1 & SQ & T2N1M0 & uveitis, BHL & 16 years \\
\hline & & & & & & left mediastinal nodes & \\
\hline 2 & 51/Male & 720 & 0 & LA & T1N0M0 & erythema, BHL & 10 years \\
\hline & & & 0 & SQ & T2N0M0 & erythema, BHL & 18 years \\
\hline 3 & 60/Female & 70 & 1 & $\mathrm{AD}$ & T1N2M0 & right lung, lymph nodes & concurrent \\
\hline
\end{tabular}

\# - age at diagnosis of sarcoidosis; LA - large cell carcinoma; SQ - squamous cell carcinoma; AD - adenocarcinoma; BHL - bilateral hilar lymphadenopathy

Tab. 2: Treatment and prognosis of 3 patients with sarcoidosis and lung cancer.

\begin{tabular}{|c|c|c|c|c|}
\hline \multirow{2}{*}{ No. } & \multicolumn{2}{|c|}{ Treatment } & \multirow{2}{*}{ p-TNM } & $\begin{array}{c}\text { Survival after surgery } \\
\text { (Months) }\end{array}$ \\
\cline { 2 - 3 } & Sarcoidosis & Lung cancer & T2N0M0 & 6 years, alive \\
\hline 1 & Steroid & left lower lobectomy & T1N0M0 & 10 years, alive \\
\hline 2 & None & partial resection of right lung & T3N1M0 & 2 years, alive \\
\hline 3 & None & right upper lobectomy & T1N0M0 & 10 months, alive \\
\hline
\end{tabular}

nant tumors. In our cases No. 1 and 2, in which lung cancer originated a very long time after the diagnosis of sarcoidosis, the sarcoidosis activity was not so high at the diagnosis of these lung cancers, so the involvement of the cell-mediated immune abnormalities were open to question. In contrast, in case No. 3, both diseases were detected simultaneously. In this case, therefore, the second to fourth speculations should be considered. Some reports supported the theory of an association between the two diseases $(3,22)$, but some reports did not $(15,17)$. Recently, Le Jeune et al (10) reported the first large cohort study to compare the incidence of cancer in patients with sarcoidosis to individuals in the general population (10). Their analysis of individual cancer types indicated that the most dramatic increases were in lymphoma (rate ratio 7.08) and skin cancers (rate ratio 1.89) (10). They were concerned that this increase in the diagnosis of skin cancers might represent ascertainment bias due to the visibility of skin lesions and increased contact with medical practitioners after a diagnosis of sarcoidosis(10). If this concern is correct, we suppose that the same ascertainment bias may apply to an increase in the diagnosis of lung cancer.

As reported in the fourth speculation by Yamasawa et al (20), sarcoid reactions have been sometimes observed in the lymph nodes draining the cancer in patients with malignant disease $(7,8,9,14)$. In addition, they may occur in the stroma, the organ of tumor origin, or distant tissue sites such as the spleen, bone marrow, and skin $(7,8,9,14)$. Sarcoid reactions refer to the development of noncaseating epithelioid cell granulomas in patients who do not fulfill the criteria for systemic sarcoidosis. A hypothesis has been shown that sarcoid reactions might be associated with a host-tumor response $(6,20)$. Although the difference between sarcoidosis and sarcoid reactions in the mechanisms of their development remains unclear, cases with simultaneous sarcoidosis and malignant disease may be helpful in elucidating the causal relationship between them. Two decades ago, two researchers reported pathological differences between genuine sarcoidosis and sarcoid reactions $(2,19)$. However, there has not yet been any established method to distinguish these two entities. In order to establish a diagnosis of sarcoidosis, it is mandatory to confirm the presence of granulomatous lesions in at least two different organs. In our case No.3, the primary lesion of lung adenocarcinoma was in the right lower lobe, but granulomas were also found in the right upper lobe, which was distant from the primary site, and in the parietal pleura, which was evaluated as another organ, judging from the direction of the lymph flow. This finding suggests that these lesions were different from the nonspecific sarcoid reactions induced by lung adenocarcinoma.

We described three cases with sarcoidosis and lung cancer. In our cases, the association of lung cancer with sarcoidosis did not change the therapeutic management of either of these two pathologies. The presence of sarcoidosis did not influence on the lung cancer prognosis. Either causality or coincidence, lung cancer, a condition that can be observed in patients with sarcoidosis, should be considered in the differential diagnosis when suspicious findings of it are discovered.

There is no conflict of interest.

There is no financial support.

\section{References}

1. Brincker H. Coexistence of sarcoidosis and malignant disease: causality or coincidence? Sarcoidosis 1989;6:31-43.

2. Brincker H. Sarcoid reactions in malignant tumors. Cancer Treat Rev 1986; $13: 147-56$ 
3. Brincker $\mathrm{H}$, Wilbek $\mathrm{E}$. The incidence of malignant tumors in patients with respiratory sarcoidosis. Br J Cancer 1974;29:247-51.

4. Cohen PR, Kurzrock R. Sarcoidosis and malignancy. Clin Dermatol 2007;25: 326-33.

5. Ellman P, Hanson A. The co-existence of bronchial carcinoma and sarcoidosis. Br J Tuberc 1958;52:218-21.

6. Gherardi GJ. Localized lymph node sarcoidosis associated with carcinoma of the bile duct. Arch Pathol 1950;49:163-8.

7. Herxheimer G. Uber karzinoma und tuberkulose, Z Tuberk 1917;27:251-8.

8. Kornacker M, Kraemer A, Leo E, Ho AD. Occurrence of sarcoidosis subsequent to chemotherapy for non-Hodgkin's lymphoma: report of two cases, Ann Hematol 2002;81:103-5.

9. Kurata A, Terado Y, Schulz A, Fujioka Y, Franke FE. Inflammatory cells in the formation of tumor-related sarcoid reactions, Hum Pathol 2005;36: 546-54.

10. Le Jeune I, Gribbin J, West J, Smith C, Cullinan P, Hubbard R. The incidence of cancer in patients with idiopathic pulmonary fibrosis and sarcoidosis in the UK Respir Med 2007;101:2534-40

11. Marschke RF. Sarcoidosis and malignant neoplasm:the Mayo Clinic experience. Sarcoidosis 1986:3:149-150.

12. McNeill M, Zanders TB, Morris MJ. A 49-year-old man with concurrent diagno- ses of lung cancer, sarcoidosis, and multiple regions of adenopathy on positron emission tomography. Chest 2009;135:546-549.

13. Nagai S, Handa T, Ito $\mathrm{Y}$, Ohta $\mathrm{K}$, Tamaya M, Izumi T. Outcome of sarcoidosis. Clin Chest Med 2008;29:565-74.

14. Pandha HS, Griffiths H, Waxman J. Sarcoidosis and cancer. Clin Oncol 1995;7:277-8

15. Romer FK Sarcoidosis and cancer. N Engl J Med 1982·306:1490.

16. Sakula A. Bronchial carcinoma and sarcoidosis. Br J Cancer 1963;17:206-12.

17. Seersholm N, Vestbo J, Viskum K. Risk of malignant neoplasms in patients with pulmonary sarcoidosis. Thorax 1997;52:892-4.

18. Shoenfeld Y, Avidor E, Eldar M, Vidne B, Levy M, Pinkhas J. Squamous cell carcinoma associated with sarcoidosis in the lung. Oncology 1978;35:112-3.

19. Thomas PD, Hunninghake GW. Current concepts of the pathogenesis of sarcoidosis. Am Rev Respir Dis 1987;135:747-60.

20. Yamasawa $\mathrm{H}$, Ishii $\mathrm{Y}$, Kitamura $\mathrm{S}$. Concurrence of sarcoidosis and lung cancer A report of four cases. Respiration 2000;67:90-3.

21. Yanagawa H, Goto H, Maniwa K, Ogushi F, Takahashi K, Monden Y, Hirose T, Sano N, Sone S. A case of resectable lung adenocarcinoma associated with sarcoidosis. Med Oncol 1999;16:216-220.

22. Yamaguchi M, Odaka M, Hosoda M, Iwai K, Tachibana T. Excess death of lung cancer among sarcoidosis patients. Sarcoidosis 1991;8:51-5.

Received: $28 / 11 / 2009$.

Accepted in revised form: 06/05/2010.

\section{Corresponding author:}

Hiroaki Satoh, MD, Division of Respiratory Medicine, Mito Medical Center, University of Tsukuba, Mito, Ibaraki, 310-0015, Japan; e-mail: hirosato@md.tsukuba.ac.jp 